\title{
Study of pozzolanic action of ground waste expanded perlite by means of thermal methods
}

\author{
Lukasz Kotwica $^{1} \cdot$ Waldemar Pichór $^{1} \cdot$ Wiesława Nocuń-Wczelik ${ }^{1}$
}

Received: 5 March 2015 / Accepted: 28 June 2015/Published online: 14 July 2015

(c) The Author(s) 2015. This article is published with open access at Springerlink.com

\begin{abstract}
The DTA/TG and calorimetric measurements were applied in testing the effect of fine-grained waste expanded perlite as an active component of cement mixtures. The studies were performed with aim to evaluate the kinetics of cement hydration and the modification of phase composition in the presence of additive. The series of mixtures were produced with perlite $2-35 \%$ added to cement. The acceleration of cement hydration was proved due to the pozzolanic reaction between the active amorphous fine-grained perlite. An attempt to elucidate the mechanism of cement-perlite interaction was presented, based on the results of bound water content by TG measurements.
\end{abstract}

Keywords Cement - Waste expanded perlite .

Hydration · Calorimetry $\cdot$ Pozzolana $\cdot$ Supplementary cementitious materials $\cdot$ Water content

\section{Introduction}

Perlite is an amorphous volcanic rock occurring mainly in the Mediterranean Sea area. Due to its glassy structure and high silica and alumina content, perlite can be classified as a natural pozzolanic material. The properties of natural perlite as a supplementary cementing material have been mentioned in some reports $[1,2]$. Crude perlite is ground

Wiesława Nocuń-Wczelik

wiesia@agh.edu.pl

1 Department of Building Materials Technology, Faculty of Materials Science and Ceramics, AGH University of Science and Technology, al. Mickiewicza 30, 30-059 Kraków, Poland and subjected to the short thermal treatment at temperature 900-1000 ${ }^{\circ} \mathrm{C}$. This results in expandation of material due to the presence of 2-6\% chemically bound water releasing with the formation of numerous pores in the structure. The pores are surrounded by an amorphous, sintered mass. As a consequence, expanded perlite shows very good insulating properties, and therefore, it can be used as lightweight aggregate in the lightweight mortar/concrete. However, a huge amount of fine-grained by-product is delivered when the natural perlite is processed. This by-product is a material of very low bulk density $\left(50-150 \mathrm{~kg} \mathrm{~m}^{-3}\right)$. Therefore, several problems appear, dealing with the hazard of dusting, as the transport and storage are concerned. The density, microstructure, mechanical properties, durability and generally the advantages and inconveniences related to the waste expanded perlite application have been reported in some works [3-6]. Obviously, this expanded perlite reveals very good pozzolanic activity too, and it can be considered as an artificial pozzolanic material, contributing to the formation of hydration products. The properties of perlite composites can be shaped by the proportions between the main constituents and by use of modifiers [3].

The investigations reported in the paper were performed in order to explain the influence of new material-ground waste expanded perlite on the hydration of ordinary Portland cement. In this work, the cement-waste expanded perlite mixtures were produced. The kinetics of hydration was evaluated with the help of calorimetric method; this method appeared many times as a best way to obtain basic information dealing with the hydraulic activity of many binders of different origin [7-9]. There are some data dealing with the kinetics of heat evolution in cement-natural perlite systems [2], as well as in the waste expanded perlite-cement systems [3]. However, because of the 
complexity of factors affecting the hydraulic activity (e.g., chemical composition of cement and perlite materials), the detailed investigations are needed in every particular case. The hydrated mixtures were examined by DTA/TG/DTG methods to separate the bound water from different hydrated phases and to correlate these data with those relating to the pozzolanic reaction of expanded perlite versus time of maturing.

\section{Experimental}

\section{Materials}

Waste expanded perlite (WEP) was produced in the commercial perlite expandation installation. Figure 1 shows the grain size distribution of waste expanded perlite as well as the ground waste expanded perlite after grinding. Table 1 presents chemical composition of waste expanded perlite used in experiments, as determined by XRF [X-ray fluorescence spectrometer (WD-XRF) Axios $\operatorname{mAX} 4 \mathrm{~kW}$, PANalytical, equipped with Rh source].

As it has been shown in the previous work [10], waste expended perlite is pozzolanic by its nature, but due to its high porosity and cellular microstructure (see Fig. 2) it cannot be used as an effective supplementary cementing material "as received." Therefore, the grinding was applied as a simple way to increase the expanded perlite reactivity. In such a way, its pozzolanic activity became higher and simultaneously the water demand of WEP-cement mixture was reduced [10]. Based on these findings, in the present work the waste expanded perlite material was ground in a ball mill for $4 \mathrm{~h}$. The change in the grain size distribution caused by grinding is presented in Fig. 1. It can be seen that there are two populations of grains-of

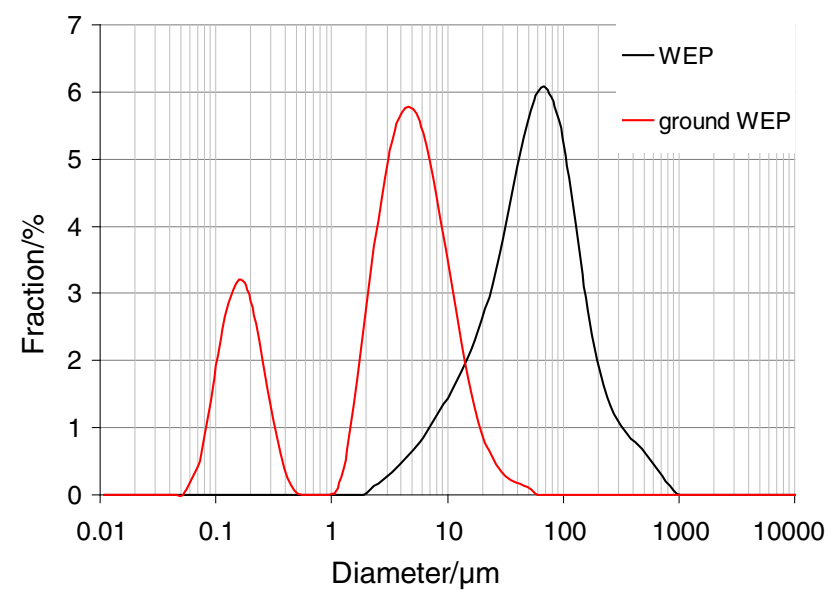

Fig. 1 Grain size distribution of waste expanded perlite "as received" and ground prior to the experiments
Table 1 Chemical composition of waste expanded perlite

\begin{tabular}{lc}
\hline Chemical compound & Content/mass\% \\
\hline $\mathrm{LOI}\left(30\right.$ min at $\left.1000{ }^{\circ} \mathrm{C}\right)$ & 0.6 \\
$\mathrm{SiO}_{2}$ & 76.2 \\
$\mathrm{Fe}_{2} \mathrm{O}_{3}$ & 1.3 \\
$\mathrm{Al}_{2} \mathrm{O}_{3}$ & 12.5 \\
$\mathrm{TiO}_{2}$ & 0.4 \\
$\mathrm{CaO}$ & 0.5 \\
$\mathrm{MgO}$ & 0.7 \\
$\mathrm{Na}$ & $\mathrm{O}$ \\
$\mathrm{K}_{2} \mathrm{O}$ & 3.1 \\
\hline
\end{tabular}

nanometric character (median equal to about $150 \mathrm{~nm}$ ) and the other one in the range of micrometers (median equal to about $3.5 \mu \mathrm{m}$ ). Morphology of grains after grinding is presented in Fig. 2.

Standard ordinary Portland cement CEM I 42.5R according to PN-EN 197-1 was used in experiments. Basic characteristic of cement is presented in Table 2.

\section{Methods}

The heat of hardening was measured in the nonisothermalnonadiabatic microcalorimeter (of our own laboratory construction, from commercially available elements, equipped with computer-controlled registration and data refinement) on the pastes produced from $5 \mathrm{~g}$ cement samples with various $(2-35 \%)$ additions of ground waste expanded perlite at constant water/cement mass ratio $=0.5$. The details of microcalorimetric experiments have been reported in the previous works [e.g., 11]. The example set of heat evolution curves is given in Figs. 3 and 4.

Amount of nonevaporable water $\left(W_{n}\right)$ was determined for the pastes prepared from the WEP-cement mixtures containing $0,5,10,20$ and $35 \%$ of ground WEP addition, respectively. Cement and perlite were dry homogenized prior to mixing. The mixtures were thoroughly mixed with freshly distilled water cooled in sealed bottle to avoid carbonation. Water/cement ratio was kept constant at 0.5 . The pastes were transferred to poly-ethylene test tubes (one for each paste and curing time) with lids, additionally sealed with parafilm and kept in water bath at temperature $25 \pm 0.1{ }^{\circ} \mathrm{C}$. After a given period of time, the samples were taken out of the test tubes, crushed with mortar and pestle. Then, they were transferred to vacuum desiccator and dried over soluble anhydrite until the mass change was smaller than $1 \mathrm{mg}$ per gram of sample per day. Then, sample was assumed to be dried to constant mass. Dry samples were ignited at $1000{ }^{\circ} \mathrm{C}$ for $2 \mathrm{~h}$. Amount of 

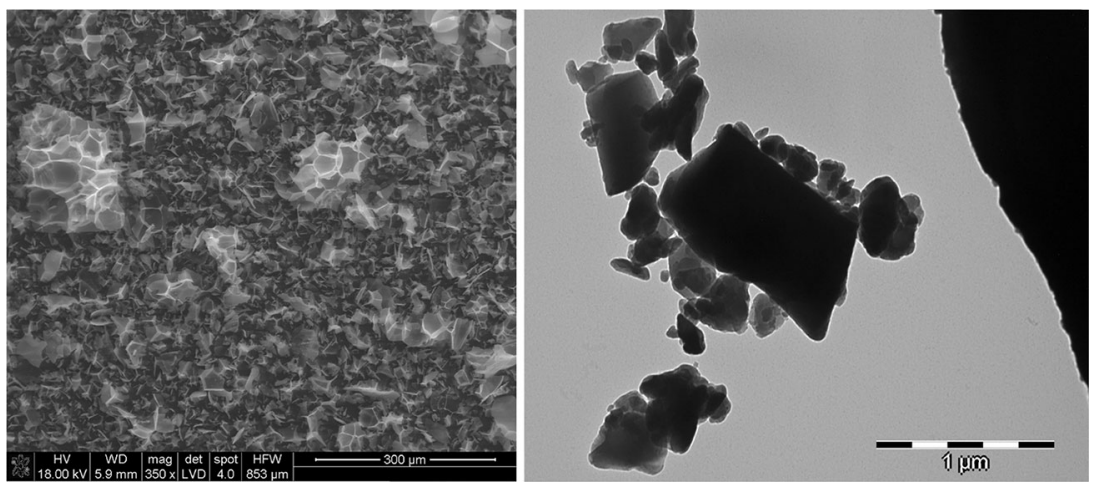

Fig. 2 Microstructure of waste expanded perlite observed under SEM (on the left) and microstructure of grains after grinding observed with TEM (on the right)

nonevaporable water was calculated on the basis of LOI and calcium carbonate content within the samples (commercial cement contains calcium carbonate as minor compound). The results are presented as mass $\%$ of ignited paste and mass $\%$ of ignited cement. This way of presentation is used in order to show the pozzolanic action of ground waste expanded perlite. Comparison of amount of nonevaporable water calculated as $\%$ of ignited paste and $\%$ of ignited paste allows to analyze reactivity of ground waste expanded perlite measured as ability to chemically bound water.

Samples with 10 and $20 \%$ addition of ground WEP together with control OPC sample were subjected to the DTA/TG analysis in order to determine calcium hydroxide content within the samples. Thermal measurements were performed with Netzsch STA 449 F3 Jupiter apparatus. Rate of heating was $10^{\circ} \mathrm{C} \mathrm{min}{ }^{-1}$. Measurements were performed in inert atmosphere of helium. Amount of $\mathrm{CH}$ was calculated on the basis of mass loss associated with $\mathrm{CH}$ thermal decomposition at about $450{ }^{\circ} \mathrm{C}$. Mass loss due to water release was determined through the digital integration of effect on DTG curve. Results were received as

Table 2 Basic properties of Portland cement

\begin{tabular}{llc}
\hline Property & Unit & Value \\
\hline Specific surface & $\mathrm{cm}^{2} \mathrm{~g}^{-1}$ & 3740 \\
Setting time & $\mathrm{min}$ & \\
$\quad$ Initial & $\mathrm{min}$ & 205 \\
$\quad$ Final & & 250 \\
Phase composition & $\%$ & \\
$\mathrm{C}_{3} \mathrm{~S}$ & $\%$ & 52 \\
$\mathrm{C}_{2} \mathrm{~S}$ & $\%$ & 17 \\
$\mathrm{C}_{3} \mathrm{~A}$ & $\%$ & 12 \\
$\mathrm{C}_{4} \mathrm{AF}$ & & 11 \\
\hline
\end{tabular}

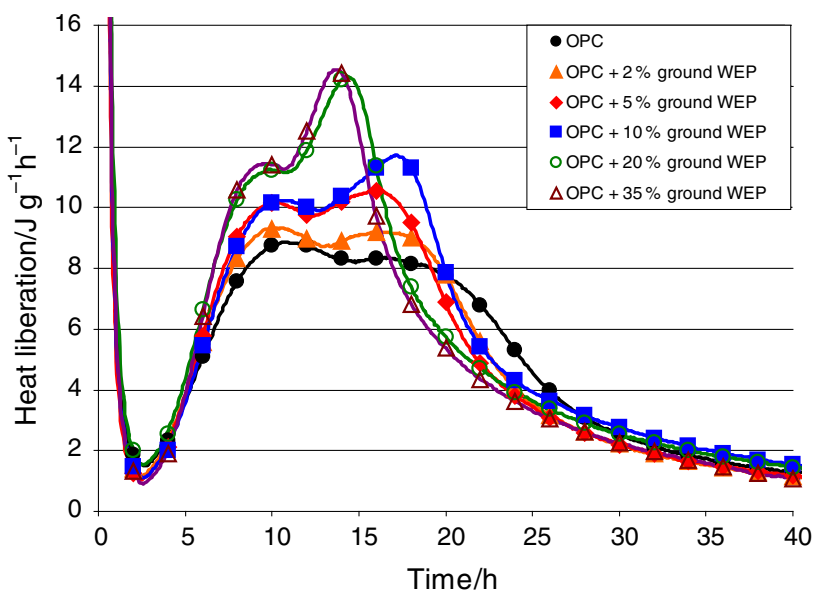

Fig. 3 Differential rate of heat evolution curves for cement pastes produced from CEM I 42.5R with perlite addition in the amount between 2 and 35 mass $\%$ (water/cement ratio $=0.5$ )

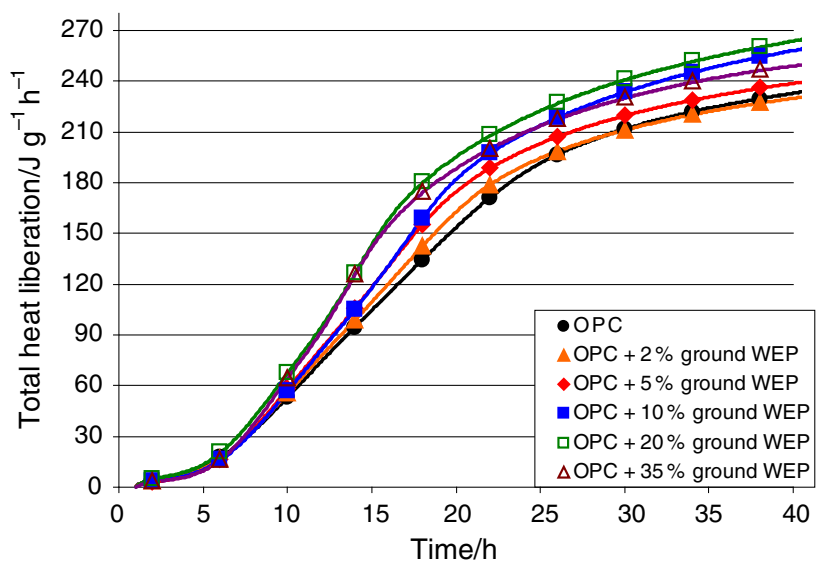

Fig. 4 Cumulative heat evolution curves for cement pastes produced from CEM I 42.5R with perlite addition in the amount between 2 and 35 mass\% (water/cement ratio $=0.5$ ) 
"mass $\%$ of paste" and recalculated to mass $\%$ of ignited paste and mass $\%$ of ignited cement.

\section{Results and discussion}

\section{Heat evolution measurements: rate of early hydration}

The calorimetric measurements were performed in order to investigate the role of perlite in cement early hydration. The mixtures of cement with $0,2,5,10,20$ and $35 \%$ of ground WEP, respectively, were processed with relevant amount of water (see Table 3). The results illustrating the rate of heat evolution changes versus time, calculated per $1 \mathrm{~g}$ of cement in the mixture, as well as the heat evolved values, are plotted in Figs. 3-5.

From the rate of heat evolution plots (Fig. 3), one can conclude that the hydration of cement is strongly affected by the presence of vitreous expanded perlite additive. Addition of perlite does not influence the induction period. The induction period length and the reaction slow down are similar to OPC control sample and samples with ground WEP addition. Differences start to be visible in acceleration period after about $5 \mathrm{~h}$ of hydration. In case of control, OPC paste, the main effect has maximum at about $8.8 \mathrm{~J} \mathrm{~g}^{-1} \mathrm{~h}^{-1}$ after about $11 \mathrm{~h}$. There is also an additional peak starting at about $15 \mathrm{~h}$ and lasting for about $7 \mathrm{~h}$. The origin of that peak is related to hydration of aluminates residue, left unreacted after induction period has finished. The addition of ground WEP causes the increase in intensity of main heat effect. The maximum of the peak is also shifted toward the beginning of hydration. The most important differences one can observe for the additional peak associated with aluminates hydration. While for the control paste this effect has the form of a shoulder, in case of modified samples it becomes significant and dominating. The intensity of second peak increases with the increase in ground WEP addition up to $20 \%$. No significant differences can be found between 20 and $35 \%$. The intensification of aluminate peak is followed by sudden decrease in

Table 3 Composition of samples used in calorimetric investigations

\begin{tabular}{llll}
\hline Sample & Cement/g & Ground WEP/g & Water/g \\
\hline 0 & 5.00 & 0.00 & 2.50 \\
2 & 5.00 & 0.10 & 2.50 \\
5 & 5.00 & 0.25 & 2.50 \\
10 & 5.00 & 0.50 & 2.50 \\
20 & 5.00 & 1.00 & 2.50 \\
35 & 5.00 & 1.75 & 2.50 \\
\hline
\end{tabular}

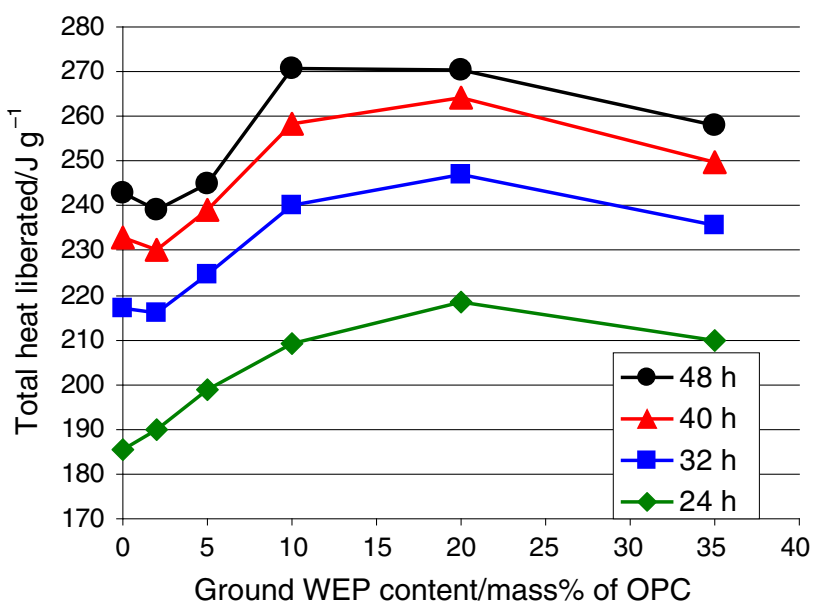

Fig. 5 Total heat evolved in the hydrating pastes modified with different amounts of ground WEP after 24, 32, 40 and $48 \mathrm{~h}$ of hydration

heat evolution rate. As a consequence in the case of pastes modified with ground WEP, the main effect is shortened as compared to the control paste.

In Fig. 4, cumulative heat evolution curves are presented. Plot begins at $1 \mathrm{~h}$, since the values determined during first hour are influenced by mixing procedure. Ground waste expanded perlite causes acceleration of cement hydration. One can see that in case of pastes modified with 5 and more mass\% of ground WEP, the amount of heat released is higher during all the investigated period. The cumulative curve for the paste with 2 mass $\%$ addition is almost interfered with the one for reference sample though the plots illustrating the rate of heat evolution versus time do not cover so exactly. In order to analyze the course of hydration of pastes quantitatively, values of total heat evolved during hydration after 24, 32, 40 and $42 \mathrm{~h}$ are presented in Fig. 5. One can notice that the highest values of heat released were recorded for paste with $20 \%$ of ground WEP introduced into the paste. It suggests that the presence of ground waste expanded perlite brings about an acceleration of cement hydration. On the basis of heat release curves, one can suppose that both alite hydration (increase of main peak intensity) and aluminates hydration (spectacular increase in intensity of "aluminate" peak) are accelerated. Moreover, the data obtained from calorimetric measurements are in agreement with results of mechanical strength tests [10]. As it has been shown in the previous investigations, 10 and $20 \%$ addition of ground WEP give best results after 24 and $48 \mathrm{~h}$ of curing as the early strength is concerned [12]. In general, it seems that the addition of ground WEP over $20 \%$ is not profitable. Not only mechanical properties become worse but also water demand of blended systems increases significantly 
for ground WEP addition larger than $20 \%$ of cement mass [12].

\section{Calcium hydroxide content}

The changes of calcium hydroxide content are an important indicator of hydration course. Pastes containing 0, 10 and $20 \%$ of ground WEP addition were subjected to DTA/ DTG analysis in order to determine the amount of calcium hydroxide within the paste. In Fig. 6, the amount of calcium hydroxide as percent of mass of ignited cement is presented. One can conclude that up to $25 \mathrm{~h}$ of hydration, ground WEP-modified pastes act similarly to neat cement paste. Later, modified pastes exhibit lower calcium hydroxide content, comparing to control sample. The decrease in the amount of calcium hydroxide is roughly proportional to the amount of ground WEP introduced into the pastes. Obtained results show that ground waste expanded perlite poses pozzolanic properties, since it causes the dramatic reduction in calcium hydroxide content within the hardened pastes. In Fig. 7, the content of calcium hydroxide for pastes containing different amounts of ground WEP is presented for $6000 \mathrm{~h}$ of hydration. One can see that the relationship is not linear. It suggests that in case of higher dosages of ground WEP, the hydration course somewhat differs from the hydration course of pastes with lower ground WEP content. The reason for that is the most probably the fact that pastes modified with ground WEP exhibit lower pore diameters and hence lower permeability. This is due to the pozzolanic action of ground WEP. The decrease in permeability of pastes results in hydration deceleration due to limited mobility of water and other substrates. It is especially important in case of pozzolanic reaction, which needs moisture to proceed. Results obtained for bound water content of pastes also confirm that observation.

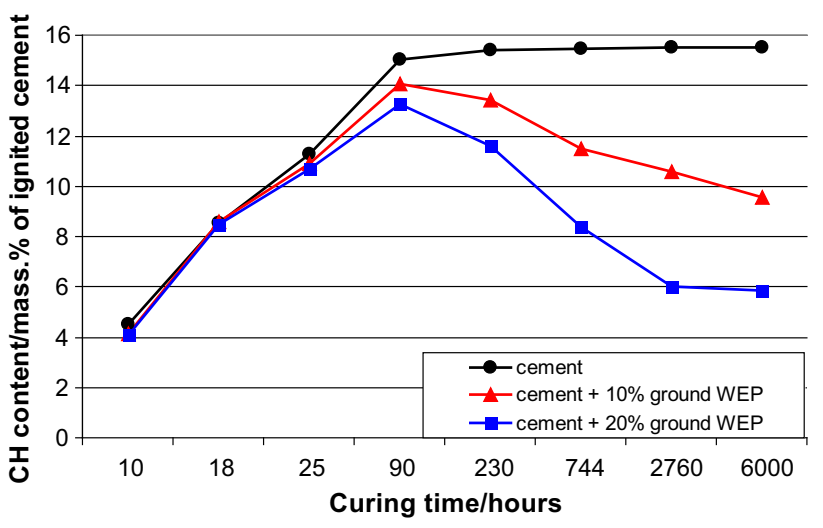

Fig. 6 Calcium hydroxide content for pastes containing 0, 10 and $20 \%$ of ground WEP. Calcium hydroxide content recalculated with respect to the percentage of cement in the initial cement + perlite mixtures, for pastes containing 0,10 and $20 \%$ of ground WEP

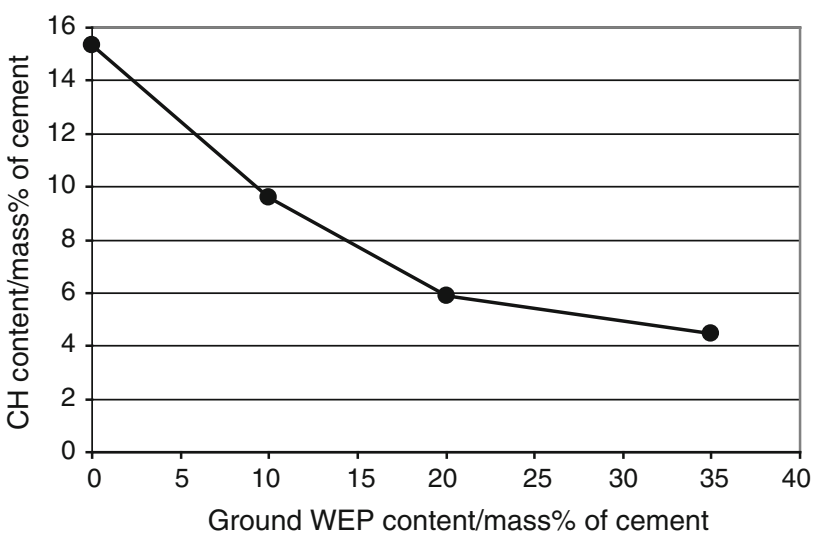

Fig. 7 Calcium hydroxide content for the pastes containing various amounts of ground WEP cured for $6000 \mathrm{~h}$

\section{Nonevaporable water content}

Figure 8 presents the nonevaporable water content in the pastes incorporating ground WEP. One can notice that from the point of view of nonevaporable water, the course of hydration can be divided into two periods. The first one occurs up to $24 \mathrm{~h}$, when the amount of nonevaporable water is approximately equal for all the pastes except the one containing $35 \%$ of ground WEP. In the following period, the amount of Wn starts to vary significantly for particular pastes. The higher the ground WEP content, the lower the nonevaporable water content. In order to avoid misinterpretation of this observation, it is necessary to have in mind that the nonevaporable water is connected with various cement hydration products and that the percentage of neat cement in the mixtures is different. Therefore, it is necessary to look at the results calculated taking into account the reduction in cement content, presented as "\% of ignited cement." Figure 9 presents the results of this calculation. Comparing the data in Figs. 8 and 9, one can

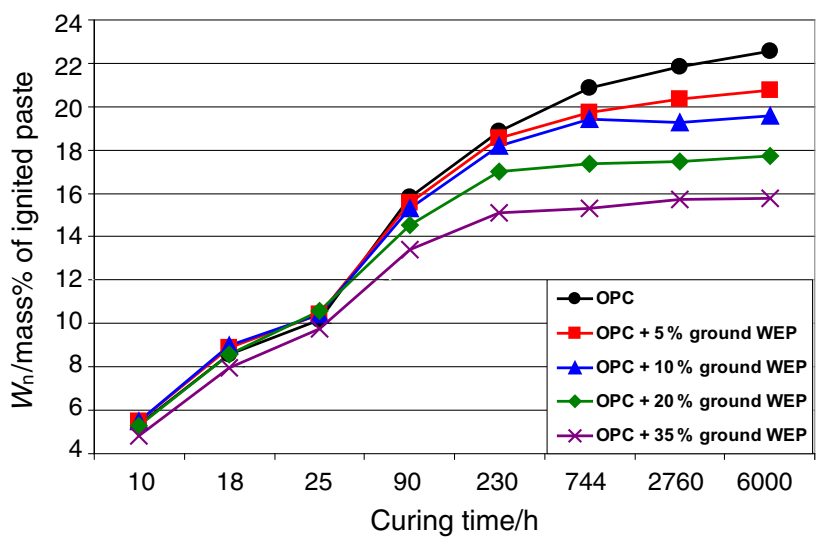

Fig. 8 Content of nonevaporable water in pastes containing various amounts of ground WEP. Results presented as mass\% of ignited paste 


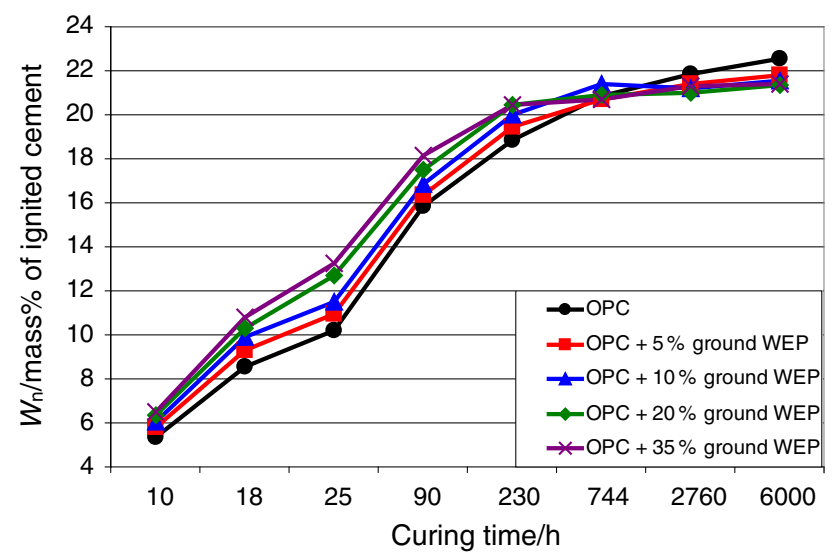

Fig. 9 Content of nonevaporable water in pastes containing various amounts of ground WEP. The results calculated taking into account the percentage of neat cement in the mixtures

conclude that in the first period of hydration, the presence of ground waste expanded perlite brings about an increase in nonevaporable water content expressed as mass $\%$ of cement. The increase is approximately so significant that the content of Wn expressed as mass\% of paste is constant up to $20 \%$ of ground WEP addition. As one can see in Fig. 6, during the first period of hydration no pozzolanic reaction was observed. It is important for further analysis of Wn content. In the second period of hydration, Wn content presented as mass $\%$ of ignited paste is lower for the pastes modified with perlite, but it is still higher than presented as mass\% of cement. One can conclude that the increase in Wn content with respect to the neat cement content results from the fact that the ground WEP takes a part in the hydration process and contributes to the formation of higher $\mathrm{C}-\mathrm{S}-\mathrm{H}$ phase amount. However, analyzing the data in Fig. 9 one can notice that after $230 \mathrm{~h}$ of hydration, the content of nonevaporable water, calculated taking into account the percentage of neat cement in the mixtures, starts to decrease with respect to nonevaporable water content in the reference neat cement paste. It could indicate the retardation of hydration process in later hydration periods and hence allow to separate the third hydration period, during which the modification of hydration by ground WEP occurs slower, comparing to the control sample. But before such conclusion may be drawn, one more issue has to be taken into account. In pozzolanic systems during the hydration, the changes in phase compositions of products are observed. They depend on the degree of cement hydration on one hand as well as on the progress of pozzolanic reaction on the other hand. It means that the proportions between $\mathrm{C}-\mathrm{S}-\mathrm{H}$ phase and calcium hydroxide can vary. It is a very important issue in the light of the fact that the content of water in calcium hydroxide is different from that attributed to the $\mathrm{C}-\mathrm{S}-\mathrm{H}$ phase. In case of calcium hydroxide, the mass ratio of water to the mass of whole compound is about $24.3 \%$. In case of $\mathrm{C}-\mathrm{S}-\mathrm{H}$ phase, taking into account the $\mathrm{C}_{1.7} \mathrm{SH}_{1.2}$ approximate formula for drying conditions [13], similar to those used in present work is, the ratio is equal to about $12.2 \%$. Therefore, as the nonevaporable water is used as an indicator of degree and rate of hydration, this fact should be regarded too. It should be taken into account that one phase containing $24 \%$ of water can be transformed into another which contains only $12 \%$ of water. It means that the total amount of water can decrease with time, despite the fact that the overall degree of hydration is increasing. It is the specific situation for active, efficient pozzolana-bearing systems. In order to avoid the misinterpretation of results in such systems, it is useful to analyze the amount of bound water incorporated into hydrated phases other than calcium hydroxide, e.g., $\mathrm{C}-\mathrm{S}-\mathrm{H}$ phase and hydrated calcium aluminates. $\mathrm{C}-\mathrm{S}-\mathrm{H}$ phase is crucial, since it is a product of both clinker minerals hydration and the product of pozzolanic reaction, but because it is impossible in practice to distinct water bound in $\mathrm{C}-\mathrm{S}-\mathrm{H}$ and hydrated aluminates, these both phases can be considered as indicators of degree of hydration in pozzolanic system.

Figure 10 presents changes in nonevaporable water content, but in this case, only the percentage of water incorporated in $\mathrm{C}-\mathrm{S}-\mathrm{H}$ phase and hydrated aluminates is taken into account. The values on the plots in Fig. 10 were obtained by subtraction of the mass of water released during calcium hydroxide thermal decomposition from the total mass of bounded water. One can see that the amount of nonevaporable water incorporated in the hydration products other than calcium hydroxide is higher in case of pastes modified with ground waste expanded perlite as compared to neat OPC paste. It allows to draw a conclusion that the degree of hydration in a system modified by pozzolanic additive is higher. Therefore, the higher the amount

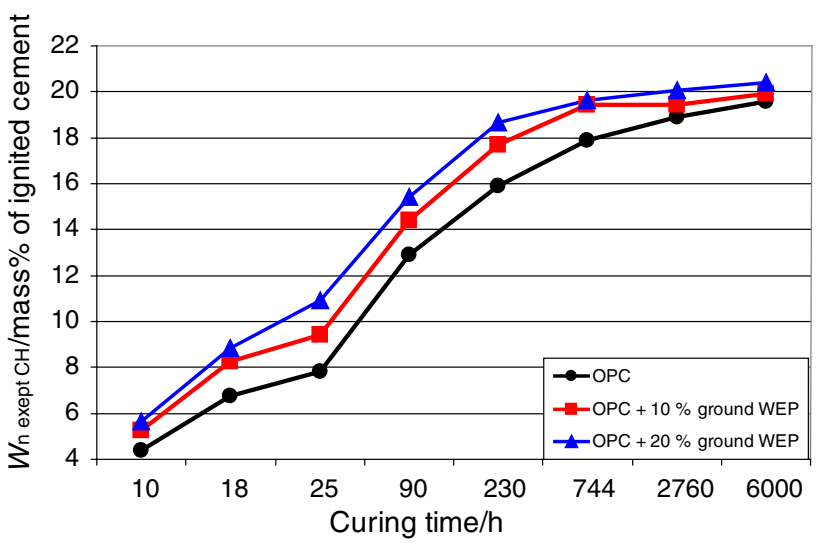

Fig. 10 Changes in amount of water bound in $\mathrm{C}-\mathrm{S}-\mathrm{H}$ phase and aluminates during hydration. Results are the difference between total bound water content and water bound in calcium hydroxide 
of perlite is, the higher the amount of hydration products, with respect to the control neat cement paste.

It can be seen that in longer periods of hydration, especially after $2760 \mathrm{~h}$, the increase in percentage of water bound in phases other than calcium hydroxide starts to decelerate for the pastes containing ground waste expanded perlite. If one connects it with the data in Fig. 7, a conclusion may be drawn that the rate of hydration in the OPC pastes modified by the ground waste perlite decreases at later age due to the reduction in permeability of hydrated cement matrix. This explains the data in Fig. 10 showing that the deceleration of bound water content growth is observed for ground WEP-bearing pastes. On the other hand, the data given in Fig. 7 can be explained too: The more the ground waste expanded perlite added, the more the additional hydration products present and the permeability of the matrix becomes lower. Therefore, for the pastes containing larger amounts of ground WEP, the efficiency of calcium hydroxide consumption is decreasing, since the pozzolanic reaction is slowed down due to the low diffusivity of the matrix and hence the lower availability of water for the reaction. The diffusion of other species, like calcium and silicates, is also seriously limited.

\section{Conclusions}

The following concluding remarks can be drawn directly or indirectly from the results presented above:

Ground waste expanded perlite is an effective pozzolanic additive to cement-based materials. It significantly reduces the amount of calcium hydroxide in the hydrating pastes. Addition of ground waste expanded perlite to OPC causes the increase in the amount of hydration products other than calcium hydroxide. The changes in rate and degree of pozzolanic reaction result in deceleration of hydration at later age for the ground WEP-modified pastes. The results suggest that it is due to the fact that the presence of waste expanded perlite results in more compacted microstructure. As a consequence, the diffusion coefficients become lower, what slows down the hydration in long periods.

Ground waste expanded perlite affects the course of OPC hydration not only in long periods, but also in early stages of hydration. The presence of ground WEP results in an increase in hydration rate during the acceleration period. It suggests that the hydration of alite is improved by the presence of ground waste expanded perlite. Other important issue is that presence of perlite significantly changes the calorimetric effect originating from hydration of unreacted aluminates. This is most probably caused by significant amount of alumina incorporated in this additive.
From the experimental point of view, the data thus obtained point the problem of distribution of nonevaporable water among the hydration product. Since the content of water in calcium hydroxide is about twice that in the $\mathrm{C}-\mathrm{S}-\mathrm{H}$ phase, the careful analysis is suggested for the systems where the pozzolanic reaction takes place, in order to avoid misinterpretations.

Acknowledgements The financial support from the Polish Ministry of Science and Higher Education (Grant No: PBS I 177206 is acknowledged.

Open Access This article is distributed under the terms of the Creative Commons Attribution 4.0 International License (http://creativecommons.org/licenses/by/4.0/), which permits unrestricted use, distribution, and reproduction in any medium, provided you give appropriate credit to the original author(s) and the source, provide a link to the Creative Commons license, and indicate if changes were made.

\section{References}

1. Erdem TK, Meral C, Tokyay M, Erdogan TY. Use of perlite as a pozzolanic addition in producing blended cements. Cem Concr Compos. 2007;29:13-21.

2. Erdogan ST, Saglik AU. Early age activation of cement pastes and mortars containing ground perlite as a pozzolan. Cem Concr Compos. 2013;38:29-39.

3. Nocun-Wczelik W, Nowak M, Trybalska B. Transport of water in expanded perlite mortars modified by admixtures. Ceram Mater. 2014;66:62-7.

4. Lanzón Torres M, García-Ruiz PA. Lightweight cement mortars: advantages and inconveniences of expanded perlite and its influence on fresh and hardened state and durability. Constr Build Mater. 2008;22:1798-806.

5. Lanzón Torres M, García-Ruiz PA. Lightweight pozzolanic materials used in mortars: evaluation of their influence on density, mechanical strength and water absorption. Cem Concr Compos. 2009;31:114-9.

6. Kramar D, Bindiganavile V. Impact response of lightweight mortars containing expanded perlite. Cem Concr Compos. 2013;37:205-14.

7. Wilińska I, Pacewska B. Calorimetric and thermal analysis studies on the influence of waste aluminosilicate catalyst on the hydration of fly ash-cement paste. J Therm Anal Calorim. 2014;116:689-97.

8. Nocuń-Wczelik W, Łagosz A, Kowalski B, Gawlicki M. Calorimetry in testing waste materials from the brown coal combustion. J Therm Anal Calorim. 2014;118:123-31.

9. Singh NB, Kalra M, Kumar M, Rai S. Hydration of ternary cementitious system: portland cement, fly ash and silica fume. J Therm Anal Calorim. 2015;119:381-9.

10. Kotwica Ł, Pichór W, Kapeluszna E, Różycka A. Waste expanded perlite used as an effective supplementary cementitious material. Constr Build Mater. 2014; (submitted to).

11. Nocuń-Wczelik W, Trybalska B, Żugaj E. Application of calorimetry in evaluation the effect of carbonate additives on cement hydration. J Therm Anal Calorim. 2013;113:351-6.

12. Kapeluszna E, Kotwica $€$, Pichór W, Nocuń-Wczelik W. Ground expanded perlite by-product as an additive to common cements. Cem Wapno Beton. 2015;1:38-46.

13. Bouwers HJH. The work of Powers and Brownyard revisited: Part 1. Cem Concr Res. 2004;34:1697-716. 